\title{
Ideological Labels in America
}

\author{
Christopher Claassen \\ Department of Government \\ University of Essex, UK \\ Patrick Tucker and Steven S. Smith \\ Department of Political Science and the Weidenbaum Center, \\ Washington University in St. Louis
}

This paper extends Ellis and Stimson's (2012) study of the operational-symbolic paradox using issue-level measures of ideological incongruence based on respondent positions and symbolic labels for these positions across 14 issues. Like Ellis and Stimson, we find that substantial numbers—over 30 percent—of Americans experience conflicted conservatism. Our issue-level data reveal, furthermore, that conflicted conservatism is most common on the issues of education and welfare spending. In addition, we also find that 20 percent of Americans exhibit conflicted liberalism. We then replicate Ellis and Stimson's finding that conflicted conservatism is associated with low sophistication and religiosity, but also find that it is associated with being socialized in a post-1960s generation and using Fox News as a main news source. Finally, we show the important role played by identities, with both conflicted conservatism and conflicted liberalism linked with partisan and ideological identities, and conflicted liberalism additionally associated with ethnic identities.

Keywords: operational ideology, symbolic ideology, identity

\footnotetext{
*Email: cclaas@essex.ac.uk; telephone: +44 1206 873494; address: Department of Government, University of Essex, Colchester CO4 3SQ, United Kingdom.
} 
The "ideology puzzle" has received considerable attention by scholars of American public opinion, including Ellis and Stimson (2012) in their superb examination of the subject. The puzzle is that Americans who call themselves conservative outnumber those who call themselves liberals and yet a majority of Americans take a liberal position on most policy issues in national surveys. Appropriately, Ellis and Stimson focus on the largest group of seemingly inconsistent Americans - those who adopt the conservative label and exhibit liberal policy views. These "conflicted conservatives" take the conservative label, Ellis and Stimson argue, because of its importance outside of politics. Traditional values, some rooted in religious commitments, lead a sizable group of Americans to adopt the conservative label even when their views about public policy appear to be liberal.

We make three contributions. First, we gain a better understanding of why conflicted conservatives outnumber conflicted liberals by identifying the issues that create the most frequent mismatches for both groups (conservative labels for liberal positions and vice versa). We do so with new data on how Americans label their positions on individual issues. Second, we extend the analysis to conflicted liberals and discover that the forces that are associated with mismatching in this direction are not the same as those that lead liberal positions to be labeled as conservative. Third, we investigate a wider range of determinants of mismatches between labels and positions. Like Ellis and Stimson, we test the effects of religiosity, political sophistication, and elite frames on respondents' likelihood of exhibiting ideological conflict at the issue level. We go beyond Ellis and Stimson to consider the effects of political identities (Conover 1984, Miller et al. 1981, Popp and Rudolph 2011) —ideological, partisan, and ethnic—as well as exposure to different media outlets and generational socialization. 


\section{The Symbolic-Operational Ideology Problem}

Previous research concludes that Americans' expectations of government are remarkably consistent. A majority of Americans take a liberal view of a wide range of federal programs and have done so in every year since 1968 (Stimson 1999). Overall, the public's policy mood may shift in the conservative direction in a given year, but the balance of opinion favors the liberal side on a wide variety of policy questions. Ellis and Stimson label the scaled issue-specific positions "operational ideology."

In contrast, when asked to identify their general or "symbolic ideology," those choosing the "conservative" label outnumber those calling themselves "liberal." Much like the longitudinal analysis of operational ideology, studies find this one-sidedness of response to be a consistent feature of American political attitudes (Box-Steffensmeier, Knight, and Sigelman 1998, Robinson and Fleishman 1984, Robinson and Fleishman 1988, Smith 1990, Erikson, MacKuen and Stimson 2002, Stimson 2004). Using a continuous time series made possible with reputable polls before 1970, Ellis and Stimson (2007) find that liberal self-identification has declined since the New Deal.

On balance, then, Americans espouse operationally liberal views, supporting a robust federal government, but at the same time more Americans consider themselves conservative than consider themselves liberal (Free and Cantril 1967, Miller 1992, Cantril and Cantril 1999, Jacoby 2000, Schiffer 2000, Stimson 2004, Ellis and Stimson 2012). The common observation about

this asymmetry is that more than a poorly informed public is at work. Something systematic creates a conservative identity for at least some Americans who take liberal positions on a variety of policy issues. 
The most significant contribution of Ellis and Stimson is their consideration of three pathways — ideological constraint, issue framing, and apolitical sources of labeling — by which Americans may acquire a mismatch of operational and symbolic ideology. First, as the longstanding theory provides (Converse 1964), ideology serves as a guide or heuristic for evaluating policy options and political elites (Jacoby 1991). We now know that this ideological behavior is conditioned upon education and previous political engagement (Stimson 1975, Knight 1985, Judd and Krosnick 1989, Jacoby 1991).

Second, the framing of political discourse by elites and the media influences how Americans characterize their ideological self-identification and policy preferences. When certain labels are emphasized or favored by political and media elites, the public is more likely to identify with them than others (Conover and Feldman 1981, Gilens 2000, Iyengar 1991, Reese, Gandy, and Grant 2001, Sears and Funk 1990). Elite framing often promotes the term "conservative," while the term "liberal" is used with much less frequency and has long had a more negative connotation. Ellis and Stimson (2007) believe that this asymmetric framing is grounded in the events of the last half-century that associated liberal views with minorities and social change, which led the public to hold, conservative identification in higher esteem (Jennings 1992, Schiffer 2000). In response, liberal elites often eschew the label in favor of "progressive" or an emphasis on the specific details of how they would address social problems (Sears and Citrin 1985), while conservative elites retain the label and attack government in general (Jacoby 2000).

Third, and most notable, Ellis and Stimson observe that there are apolitical bases for adopting the conservative label. Some Americans, they argue, associate the conservative label with traditional values, including religious values, patriotism, and temperance, which leads them 
to choose conservative as the label best fitting their own identity in response to standard survey questions about ideological identity (Kellstedt and Smidt 1991). For such Americans, the conservative label is preferred to the liberal label, although many of them choose liberal positions on contemporary political or policy issues.

In the Ellis and Stimson account, it is the category of "conflicted conservatives" who are responsible for most of the mismatch between aggregate statistics on symbolic and operation ideology. Conflicted conservatives are distinctive for being less well educated, less knowledgeable and engaged, less affluent, more white and suburban, and more likely to live in traditional family structures than unconflicted conservatives and liberals (Ellis and Stimson 2012, 152). They "believe that government policies should be guided by principles of caution, restraint, and respect for traditional values, moral and economic" (Ellis and Stimson 2012, 177) and adopt "conservative" as a label for what may be an "extra-political” identity, but nevertheless, on balance, hold liberal views on a range of public policy issues. That isremarkably — at least some people respond to the standard self-placement survey question, "when it comes to politics, do you usually think of yourself as...," in a non-political way.

Other studies do not contradict the general empirical argument of Ellis and Stimson about the mismatch of symbolic and operational ideology, but the theoretical narratives diverge from the Ellis-Stimson account in important ways. One account emphasizes the bidimensionality of American political preferences; the other emphasizes that different evaluative processes may operate for the choice symbolic label than for the responses to issue questions.

The first critique is implicit in the observation that Americans' policy preferences are not unidimensional, even in an era of partisan polarization, and are probably best characterized by at least two dimensions, an economic or social welfare dimension and a social, moral, or cultural 
dimension (Feldman and Johntson 2013, Layman and Carsey 2002, Shafer and Claggett 1995, Treier and Hillygus 2009, Zumbrunnen and Gangl 2008). These two dimensions are only modestly correlated: at 0.30 in Treier and Hillygus (2009) and 0.21 and 0.36 in Feldman and Johnston's (2013) two samples. Shafer and Claggett (1995) infer that the two dimensions of American political attitudes create "two majorities" with different social and political compositions. Since the correlation between the two dimensions is modest, the dimensions exhibit quite different distributions of individuals and the analytic application of "liberal" and "conservative" labels to both dimensions becomes problematic.

Indeed, if the symbolic labels that people choose reflect some aggregate of the location across the two incommensurable dimensions, many Americans must struggle to apply the labels. In fact, as Fiorina et al. (2005) emphasize, a plurality of Americans identify themselves as "moderate" or reply "don't know" when asked, "When it comes to politics, do you usually think of yourself as extremely liberal, liberal, slightly liberal, moderate or middle of the road, slightly conservative, conservative, extremely conservative, or haven't you thought much about this?" Moreover, we have known for some time that individuals with a mix of attitudes tend to choose "moderate" as their label more than individuals with more "consistent" attitudes (Alvarez and Brehm 1995, Treier and Hillygus 2009).

More recent research has shown that not only are there are at least two dimensions of policy preferences, individuals vary in the salience they ascribe to each, and thus in the manner in which they fashion belief systems out of the two dimensions (Feldman and Johnston 2013, Baldassari and Goldberg n.d.). Some individuals adopt the unidimensional liberal-conservative continuum espoused by elites, and are thus liberal (or conservative) on both dimensions. Other individuals only show coherent belief systems on one of the two dimensions of ideology, with 
reliably liberal (or conservative) views on these issues, and disorganized views on the other dimension. Baldassari and Goldberg (n.d.) suggest that there is a further group of individuals who do not exhibit an organized belief system on either of the dimensions. This research presents perhaps the sharpest challenge to Ellis and Stimson's account, suggesting that the operationalsymbolic paradox may be no more than a manifestation of the varying saliences that individuals ascribe to each ideological dimension.

Unfortunately, the Ellis-Stimson analysis of dimensionality is somewhat ambiguous. One treatment of the subject (Ellis and Stimson 2012, Chapter 3) is based on the Stimson mood measures and finds, with a nonorthogonal rotation of factors, that two dimensions emerge but are correlated at 0.80. This leads to the inference that the two dimensions exist but few Americans have conflicting views across the two dimensions. A second treatment of the subject (Ellis and Stimson 2012, Chapter 5), based on the spending questions in the General Social Survey, also finds two dimensions, but the two dimensions are correlated at only 0.20 and both have a significant and nearly equal correlation with symbolic ideology (Ellis and Stimson 2012, 109 and 119). The second treatment suggests the existence of many conflicted Americans and is consistent with most other studies. In that analysis, Ellis and Stimson find that over a quarter of self-identified liberals do not hold liberal policy positions on both dimensions (Ellis and Stimson 2012, 109-110). This number is much smaller than the 80 percent of self-identified conservatives who hold a liberal balance of policy positions on one of the two dimensions, but the conflicted liberals appear to be a group that warrants analysis, as the Treier and Hillygus findings suggest.

A second critique can be read in Popp and Rudolph's (2011) distinction between ideology as an identity and ideology as a principled belief. These authors argue that the classical view of 
ideology as an overarching and constraining belief system (Converse 1960, Feldman 1988) is too simple. Instead, ideology entails two separate evaluative processes. The first is indeed the classical belief system: a set of core principles about the proper role of government that is closely related to operational ideology. The second, however, sees ideology as a set of identities (Conover and Feldman 1981, Zschirnt 2011): an affective attachment to ideological groups and their attendant symbols. This second evaluative process is thought to underpin symbolic ideology.

Popp and Rudolph's two-process theory severs the logical link between operational and symbolic ideology. In doing so, they turn the operational-symbolic paradox on its head: while authors like Ellis and Stimson focus on the substantial proportions of individuals who have conservative symbolic and liberal operational ideologies, the two-process theory suggests that we cannot necessarily expect to see congruence between symbolic and operational ideologies. Indeed, while Ellis and Stimson regard the relationship between liberal symbolic and liberal operational ideology to be straightforward, Popp and Rudolph, using different measures, find slightly more conflicted liberals than conflicted conservatives (13 versus 10 percent).

\section{The Present Study}

We replicate Ellis and Stimson's analysis, taking heed of the critiques implied in the bidimensionality and two-processes theses, and then seek to extend our understanding of the operational-symbolic paradox. Our primary innovation is to focus on the level of issues, rather than the level of general operational and symbolic ideologies. This contrast in levels of granularity, coupled with the distinction between operational beliefs and symbolic attachments, yield the possibilities described in Table 1: operational preferences may exist both at the issue 
level (which we call "issue positions") and at the level of general ideology ("operational ideology"); labels may be similarly applied to one's general ideology (“symbolic ideology") and one's particular issues positions ("issue labels"). Ellis and Stimson compare general orientations: symbolic (self identity) and operational ideology (aggregated issue scales). While we have these measures we also gather and analyze issue level data on positions and symbolic labels.

\section{[Table 1]}

While creating operational ideology scales by aggregating over issues can be justified on the grounds of improved measurement of the underlying attitudes, there is a cost. Because issue positions are likely to vary in their distributional properties and salience, the aggregation over multiple issues may camouflage the nature of the issues that cause a mismatch between symbolic labels and issue positions. Viewed using scaled, general-level data, the operational symbolic paradox may be no more than the differing salience that citizens attach to different issues, or different issue dimensions. Issue-level data will allow us to determine whether some issues contribute disproportionately to the mismatch of symbolic and operational ideology.

Moreover, we do not know whether Americans label their issue positions on specific policy questions as analysts do. Analytically-defined "conflicted" respondents may not be conflicted in their own eyes and the "unconflicted" respondents may exhibit more mismatches of positions and labels than we appreciate. To determine whether "mismatching" extends to issue labels, we must inspect the way that survey respondents assign labels to their issue positions.

In addition to evaluating issue-level data, we extend the Ellis-Stimson analysis by considering ideological incongruence in both directions - conflicted liberals as well as conflicted conservatives. While Ellis and Stimson set aside the former because there are few in their sample, Popp and Rudolph find similar numbers of conflicted liberals and conflicted 
conservatives. In any case, we question the justification for setting aside conflicted liberals. If Ellis and Stimson are correct, conflicted conservatives are a distinctive group-whose incongruence is characterized by low knowledge and high religiosity—but this claim would be stronger if we could demonstrate that conflicted conservatives and conflicted liberals are different in significant ways. If, on the other hand, they are similar-say, both groups are comprised of unsophisticated, apolitical people who misuse ideological labels for themselves and issues - then much of the Ellis-Stimson argument must be reconsidered.

We report our findings in two parts. Our issue-level data on policy positions and the corresponding symbolic labels that respondents attach to these is unique, so we expend much effort in bivariate analyses. We examine the degree of ideological congruence at both the general and issue levels. We also take a closer look at the correspondence between general symbolic labels and those used for particular issues. Finally, we examine position-label incongruences by issue, which also permits a test of the multidimensionality thesis outlined above.

Second, we conduct multivariate analyses of the determinants of operational-symbolic ideological incongruence, using both general and issue-level measures. Like Ellis and Stimson, we conduct these analyses for conflicted conservatives, but we also extend the analysis to conflicted liberals. This analysis permits us to re-test and extend the Ellis and Stimson thesis and test additional hypotheses derived from other studies. These hypotheses are outlined in the next section.

\section{Determinants of Symbolic-Operational Inconsistency at the Issue Level}

Ellis and Stimson $(2007,2012)$ identify three pathways for the acquisition of symbolic ideology: ideological constraint, the framing effects of elite political discourse, and the influence of 
nonpolitical identities and values. We accept those hypotheses as possible determinants of issuelevel symbolic-operational inconsistency, but expand on the Ellis-Stimson analysis in three ways. First, following Popp and Rudolph (2011), we give more explicit and extensive attention to group identity as a source of mismatch between positions and labels. Second, following the bidimensionality thesis, we test for the relative effects of economic and cultural beliefs on issuelabel mismatching. Finally, we provide additional measures of Ellis and Stimson's second pathway: the framing effects of elite political discourse.

Identities. Social identity is the categorization of the self as a member of a social group. So categorized, individuals become attached to their identities, perhaps even deriving esteem from them (Tajfel 1981). Identities thus have the power to shape individual beliefs and evaluations. In particular, identification with a group produces conformity to the group's prototype goals and beliefs (Turner 1991). A wide variety of group identities have been linked with variation in political beliefs or attitudes (e.g., Conover 1984). We focus on three in particular: ideological, partisan, and ethnic identities. We hypothesize that identification with any these groups might shape the degree to which individuals match ideological labels to issue positions.

Ideological Identities. Popp and Rudolph's (2011) distinction between ideology as a set of identities and ideology as a coherent belief system suggests that ideology may play two contrasting roles in position-label mismatches. In particular, operational ideology is expected to play the familiar constraining role, reducing incongruence between positions and labels. Identity plays a distorting role in the operational-symbolic paradox because individuals' attachments to their ideological groups may override the constraining role played by their belief system. Of course, in Ellis and Stimson's analysis of incongruence at the general level of operational and 
symbolic ideologies, symbolic identification is the outcome, and thus cannot be used as an explanation. At the issue level, which we examine, we expect that ideological identities will generate incongruence between positions and labels for some people.

Partisan Identities. Partisan identity has occupied a prominent role in political behavior since The American Voter (Campbell et al. 1960). These identities influence policy attitudes through a number of processes, including priming, cue-taking, framing, projection, and dissonance reduction (Alvarez and Brehm 2002; Feldman 1988; Goren 2005; Green, Palmquist, and Schickler 2002; Sniderman and Stigliz 2012). We expect that party identities will influence ideological congruence due to the differing sentiments toward the conservative and liberal labels in contemporary American politics: the former being viewed more favorably than the latter (Schiffer 2000). We also know that Democratic elites emphasize their policy positions and avoid using the liberal label, while Republican elites freely emphasize conservative labels (Ellis and Stimson 2012). We thus hypothesize that Democrat party identifiers will similarly focus on issue positions rather than labels and avoid the liberal label. Republicans, in contrast, will embrace the conservative label, perhaps using it at times considered inappropriate by the analyst.

Ethnic Identities. The New Deal, Great Society, and the civil rights movement altered the relationship between major ethnic groups on ideological and partisan labels. Given the links among liberal policies, the group interests of black Americans, and cues from black elites, we hypothesize that individuals identifying as African American are likely to favor the liberal label, perhaps to the extent of using this label to describing conservative issue positions. For similar reasons, we hypothesize that identifying as Hispanic produces a favorable view of liberalism and a commensurate increase in the likelihood of making conservative position-liberal label mismatches (Clawson and Trice 2000). 


\section{Framing Effects of Elite Political Discourse}

Sophistication. A vast body of research examines how knowledge of politics and government affects citizens' evaluation of policy (Wittkopf 1990; Feldman and Steenbergen 2001). At an early stage, the authors of The American Voter (Campbell et al. 1960, Converse 1964) demonstrated that the most sophisticated individuals are most likely to identify their political views correctly as liberal or conservative, and that those lacking in political sophistication tend not to identify themselves as liberals or conservatives. Others find evidence to support the view that the more politically sophisticated a respondent is, the more likely she is to have a strong connection between issue preferences and ideological labels (Delli Carpini and Keeter 1996, Zaller 1992, Goren 2004) and show less consistency of preferences (Feldman 1988, Goren 2004). This line of research suggests that less sophisticated citizens have a weaker grasp of the standard usage of political terminology, such as symbolic labels, than more sophisticated citizens. "Mismatches" of issue positions and labels are expected to be inversely correlated with sophistication.

Exposure to Specific Media Outlets. Ellis and Stimson propose that elite discourse helps shape conservative identification and the subsequent operational-symbolic divide. Media elites are particularly likely to use the liberal and conservative labels, especially in a normative fashion. In particular, the authors provide empirical evidence indicating that major media outlets such as USA Today and The New York Times are not only more likely to use the word "conservative" than "liberal" in a political context, they are also more likely to use the word "conservative" in a non-political context. Furthermore, such news outlets are more likely to 
attach positive connotations to "conservative" than they are to "liberal," and to attach negative connotations to the word "liberal."

Ellis and Stimson $(2012,169-173)$ test for the effects of news exposure with a measure on which survey respondents were asked to indicate the number of days on which they read a newspaper or watched network television news. Overall, there is no measurable effect of news exposure on being a conflicted conservative, although the middle third of respondents on a political knowledge scale exhibit a small effect. This middle tier is deemed most likely to be both open to the reception and acceptance of elite framing.

As a test of the media effects, the Ellis-Stimson analysis is limited. While it captures overall news exposure, it does not distinguish news sources and so does not test the selective exposure thesis that has taken on greater significance as the variety of news sources has multiplied (Best, et al. 2005, Mutz and Martin 2001, Mutz 2006, Stroud 2008, Taber and Lodge 2006). That is, individuals, perhaps by choice, are exposed to homogeneous, politically biased, and partisan frames that affect their interpretation of the political world, their views on issues, the labels they use, and their ideological identities. Strong ideological identities may guide the choice of media to consume so the effects of identity and exposure may be duplicative or additive.

We take a step beyond the Ellis-Stimson analysis to consider the relationship between exposure to various television networks and mismatches in labels and policy positions. The working hypothesis is that, all things being equal, exposure to biased media news coverage is associated with a greater commitment to a conservative (or liberal) label, whatever one's views on individual policy issues, and create more frequent mismatches. 
Generational Socialization. Ellis and Stimson note that the term liberal assumed its distinctive meaning in the US context in the 1930s. It also became tainted in the late 1960s. Their argument suggests that generational effects may play a role in the extent to which the liberal label is over- or under-used. Individuals reaching adulthood in the late 1960s or later would likely have developed a distinctive set of connotations attached to the word "liberal." We hypothesize that these generations of Americans avoid the liberal label compared to earlier generations. They will, moreover, be attracted to the conservative label. We should see an increase in liberal policy-conservative label mismatches in generations reaching maturity after 1965 , as well as a decrease in the reverse pattern of mismatches.

Religious Values and Identity. The final of Ellis and Stimson's arguments is that religiosity, or intensity of religious practice, is linked with ideological inconsistency. Many Americans encounter religious symbols on a weekly or even daily basis, but limit their attention of politics to electoral cycles (Beatty and Walter 1989). As a result, they may be more familiar with the term "conservative" as it relates to religion and morality. Religious conservatism is an important part of a churchgoer's identity (Leege and Kellstedt 1993). There is a prominent exception to this line of argument. Putnam and Campbell (2010) find that differences in opinion on most issues between the least and most religious citizens are actually quite small; only the social or cultural issues of abortion and same-sex marriage produce large divergences. We infer that religious practices should affect the frequency and direction of ideological mismatches, although Putnam and Campbell suggest that there is an interaction effect with issue dimension. Those who attend religious services, regardless of denomination, should encounter conservative symbols more often. For this reason, they too will be more likely to apply a conservative label to describe a political position. 
Ellis and Stimson recognize that religious affiliation may be a source of identity, but they do not examine the relationship between being a conflicted conservative and denominational affiliation. Instead, they consider biblical literalism to be a core belief of religious conservatives and find that it is related to symbolic ideology (Ellis and Stimson 2012, 128-131, 138-140). We consider both religious conservatism and religious affiliation by comparing evangelical Christians to other citizens.

\section{The Bidimensionality of Operational Ideology}

The bidimensionality thesis implies that mismatches between issues and labels may be a function of the two dimensions of operational ideology. An individual may, for example, hold conservative preferences on the dominant economic dimension of ideology, with a commensurate conservative symbolic identity, but liberal preferences on cultural issues. If a single dimension of operational ideology is aggregated from this individual's disparate preferences, it may appear that she is operationally liberal but symbolically conservative. We test the separate effects of economic and cultural beliefs on position-label mismatches.

\section{Methods and Data}

Data for our analysis are drawn from The American Panel Survey (TAPS). TAPS is a monthly online panel survey of over 2,000 people. Panelists were recruited as a national probability sample with an addressed-based sampling frame in the fall of 2011 by Knowledge Networks (now GfK Knowledge Networks) for the Weidenbaum Center at Washington University. Individuals without internet access were provided a laptop and internet service at the expense of 
the Weidenbaum Center. In a typical month, over 1,700 of the panelists complete the online survey. More technical information about the survey is available at taps.wustl.edu.

Data on policy preferences were available for 1,725 respondents from surveys conducted in December 2011 and February 2012. Item non-response within this sub-sample was tackled using the method of multiple imputation, where ten unique datasets were created using an algorithm to stochastically impute missing values for each dataset (see Rubin 1987). All estimates are weighted by the inverse of the probability of selection into the sample.

Respondents were asked for their positions on 22 issues that were selected to represent different areas of American domestic and foreign policy (see Table S1 in the supplementary materials for item wording). To focus our attention on the policies that are most central to politics, we selected 14 of these items, using two criteria. First, to be comparable to Ellis and Stimson, foreign policy items were dropped (these focused on defense spending, international trade, the war in Afghanistan, and democracy promotion abroad). We then excluded four additional questions tapping preferences for low-salience policies that were only weakly correlated with than other items (support for farm subsidies, nuclear power, campaign finance reform, and domestic wiretapping). Fourteen items remain; these form the set of issue position and labels utilized in this analysis.

Issue positions are measured on a five-point scale (strongly agree, agree, neither agree nor disagree, disagree, strongly disagree). After answering each of these questions, respondents were asked to label their position on the issue as "conservative," "moderate," "liberal," or "none of these." Central to the following analysis is the notion of a mismatch between the issue position and the corresponding label. A mismatch occurs when either of the two liberal positions on the five-point scale (directionality determined in scaling) is matched with a conservative label 
or either of the two conservative positions is matched with a liberal label. Moderate issue positions and labels, and the label "none of these," are not counted as mismatches.

\section{Findings}

\section{The Symbolic-Operational Paradox at the General and Issue Level}

The cross-tabulation of symbolic and operational ideology is shown in Table 2. The most obvious feature of the table is that the column percentages (lower left in each cell) confirm four central facts of the Ellis-Stimson argument. First, operational liberals outnumber operational conservatives. Second, symbolic conservatives slightly outnumber symbolic liberals. Third, symbolic liberals are almost entirely operationally liberal and symbolic moderates lean liberal, too. Finally, conflicted conservatives (symbolic conservatives who scale on the liberal side on issue positions) outnumber conflicted liberals.

[Table 2]

It is equally important to recognize the row percentages. A sizable majority of operational conservatives call themselves conservatives and most of the rest call themselves moderates. In contrast, operational liberals are split about equally between self-identified liberals and moderates, with a few conservatives. It is tempting to see this as confirming evidence that the liberal label is socially undesirable even for "true" liberals, but we do not have direct evidence of perceived desirability.

The frequency of mismatches between issue positions and issue labels is then reported in Table 3. For this table, the unit of analysis is a respondent's issue position and label so that an individual is included 14 times, once for each of the 14 issues. The standard ideological labelsconservative, moderate, liberal—were chosen as labels for issue positions nearly four-fifths of 
the time. "None of these," a conspicuous option presented with the standard labels, was a response about one-fifth of the time. For moderate issue positions (the middle response), "none of these" was the plurality choice of label (42 percent), in contrast to about 16 percent for liberal and conservative positions.

[Table 3]

Looking at the row percentages in Table 3, only 32 percent of the issue positions that we would label "liberal" are labeled liberal by respondents and 40 percent are labeled "moderate." In contrast, half the conservative positions are labeled conservative, with a further quarter labeled moderate. The percentage of conservative positions labeled liberal (eight percent) is lower than the percentage of liberal positions labeled conservative (12 percent), but the difference is modest. There is little difference in the frequency of "none of these." We thus infrequently observe liberal positions coupled with conservative labels and conservative positions coupled with liberal labels. Nearly all of the difference in choice of labels between conservative and liberal positions is in the use of the moderate label.

Looking at the column percentages in Table 3, conservative labels get applied to liberal positions over 22 percent of the time, while liberal labels are applied to conservative positions only 14 percent of the time. As for the symbolic-issue position mismatch, conservative labels are more likely to be used "correctly" than liberal labels, although the imbalance between conflicted conservative and conflicted liberal uses is not nearly as great.

Only eight percent of position-label pairs consist of significant mismatches of the liberal or conservative label to the opposing position. Instead, most mismatches between issue positions and issue labels involve the moderate label—and, indeed, liberal positions labeled as moderate are the most common kind of mismatch between issue positions and labels. It is entirely possible 
that this is not an "error" or "mismatch" at all, but rather it is a product of the questions and response sets that lead some respondents to favor a liberal (or conservative) issue position (say, more spending on education), arbitrarily set to be on one side of the "neither agree nor disagree" middle option and still recognize that as a moderate position. For the regression analysis that follows, we do not consider a liberal position/moderate label or conservative position/moderate label pair to be a mismatch.

At the level of issue positions and issue labels, the asymmetry between conflicted conservatives and liberals is not as great as it is at the general level, between symbolic and operational ideology. As a result, we have more cases of conflict between conservative labels and liberal issue positions to study. We consider the determinants of this type of mismatch below along with the more numerous cases in which a liberal label is applied to a conservative position. We will show that the correlates of a mismatch are not the same for the two directions. 


\section{Symbolic Ideology and Issue Labels}

The relationship between ideological identity (symbolic labels) and issue labels is complicated, primarily by our introduction of "none of these" as an option as an issue label. For some issues (Table 4), as many as a third of the respondents choose "none of these" over conservative, moderate, and liberal as a label for their issue position. This may reflect (a) a way to resolve a conflict between a symbolic identity and an issue position, (b) uncertainty about the appropriate label, or (c) a belief that the standard labels do not apply to the issue. In Table 4, we list the 14 issues in the order of frequency of the "none of these" response for respondents who report a conservative, moderate, and liberal ideological identity.

[Table 4]

For all three symbolic labels, positions on taxing the wealthy, education, same sex marriage, and abortion are readily labeled with the standard labels. Taxing the wealthy and education spending are traditional economic issues, while same sex marriage and abortion are typically classified as social or cultural issues (Ellis and Stimson 2012, Treier and Hillygus 2009). Nevertheless, these four issues are distinctive with respect to the ease with which Americans use the traditional labels.

In contrast, positions on Medicare and social security are frequently labeled "none of these" by conservatives, moderates, and liberals. Plainly, these issues are salient programs and are subject to considerable debate between conservative and liberal elites, but many Americans, nearly a third, do not choose to use the traditional ideological labels to characterize their views. A reasonable hypothesis is that conservatives use "none of these" as a way to avoid explicit conflict between their ideological identity and issue position in support of these programs, but it turns out conservatives are not much different from liberals and moderates in this respect. It 
seems more likely that these programs are popular and so well accepted that many Americans do not perceive the standard lines of political conflict to be relevant to them. If so, the issues may not scale well (and they do not) because of the lopsided marginal in support of the programs.

Moderates are much more likely than liberals and conservatives to choose "none of these" as a label for their issue positions and they do so more consistently. Many moderates may choose the moderate label for themselves because they do not or refuse to see the political landscape in liberal-conservative terms. Other moderates may not be capable of applying the standard terms and so opt for "none of these."

\section{[Figure 1]}

In Figure 1, the relationship between symbolic ideology and issue labels is shown. Aggregating the classification of policy preferences across all 14 issues provides insight into how label application differs across the three major symbolic ideological groups. Symbolic conservatives demonstrate a strong attraction to identifying their positions as conservative (roughly 49 percent) and an equally strong aversion to labeling their preferences as liberal (about six percent). Still, our results indicate that a slight majority of all issue labeling among symbolic conservatives involves a non-conservative term, with the moderate label chosen often. Symbolic liberals are a different story. More often than not, one who identifies as a liberal in the general sense will classify their policy position as moderate than liberal. Finally, symbolic moderates do not appear to favor liberal classifications over conservative ones, or vice versa. Rather, "moderate" or "none of these" make up nearly two-thirds of all symbolic moderate labeling of preferences.

\section{Economic Versus Cultural Issues}


Further disaggregating the issue-level patterns, we show the frequency of mismatches between issues positions and labels in Figure 2, where economic issues are distinguished from cultural issues. Again, liberal issue positions labeled conservative outnumber conservative issue positions labeled liberal. Moreover, while conflicted liberalism is produced in both economic and cultural issues, conflicted conservatism is largely produced by conflict on the economic dimension. In fact, most of the liberal operational - conservative symbolic conflict displayed in the left column of Figure 2 occurs on the popular programs of Medicare, education, and Social Security. These popular programs are well established and bring conservative elites to their defense (often in the form of "reform to save" the program). It may not be surprising, then, that individuals disposed to use conservative labels apply their favorite label to an issue position that they hold along with the vast majority of other Americans.

[Figure 2]

Conflicted conservatism at the issue level appears to be attributable to individuals who support continued education and welfare spending, but who couple these liberal positions with conservative identities. The role of economic and cultural ideology in shaping both conflicted conservatism and liberalism will be tested further in the regression analyses in the next section.

\section{Multivariate Analysis of the Determinants of Mismatching}

Next, we pursue multivariate analyses of the determinants of mismatching labels and positions. Estimates of multivariate models will allow us, first, to test whether the determinants of mismatches for issue-level symbolic labels and positions are the same as they are for generallevel symbolic and operational ideology. These models will also allow us to extend the analysis 
of Ellis and Stimson by testing the effects of group identities, sophistication, media sources, and generational differences on ideological incongruence.

Tables 5 and 6 report parallel estimates for our two levels of analysis: the mismatch of symbolic and operational ideology at the general level, and the mismatch of positions and labels at the issue level. Table 5 tests the determinants of general-level mismatches. We construct the dependent variables for these models in the same ways as Ellis and Stimson: for each of the 14 issues, a respondent is given a $+1,0$, or -1 for liberal, neutral, and conservative issue positions, the values are summed, and a positive score is treated as a liberal operational ideology, with positions a negative score regarded as a conservative operational ideology. These are compared to the chosen symbolic label to create a dichotomous dependent variable for whether the respondents' operational and symbolic ideologies match or not.

For Table 6, the dependent variable is the number of mismatches between issue positions and labels across the 14 issues. A mismatch occurs when respondents use the conservative (liberal) label to describe a policy preference in the liberal (conservative) direction. ${ }^{1} \mathrm{~A}$ "moderate" label or middle issue position is not categorized as a mismatch. Therefore, our estimates may well be a lower bound on the true extent of label-issues mismatches.

\footnotetext{
${ }^{1}$ The mismatch variables can be described using binomial distributions, being counts of the number of "successes" out of the 14 "trials" we asked each respondent to conduct. Logistic-binomial regression models are thus used. In the same way that the binomial distribution is a more general version of the Bernoulli distribution that is used to model dichotomous variables, the logistic-binomial regression model is a generalization of the much more well-known logit. See Gelman and Hill $(2007,116-8)$ for more details.
} 
In contrast to Ellis and Stimson, who set aside conflicted liberals for most of their analysis, we include mismatches in both directions for both levels of analysis. Because the determinants may (and prove to) be different for the two directions, we estimate the effects of the possible determinants separately for mismatches between liberal labels and conservative positions, and vice versa.

Ideological Incongruence at the General Level. The models that most closely replicate the Ellis-Stimson analysis are reported in Table 5, particularly the second column, which displays the results of the regression of whether respondents were conflicted conservatives. Like Ellis and Stimson, we find that being politically unsophisticated, religious, and having a strong ideological identity are all associated with a greater probability of being a conflicted conservative. Identifying as a Democrat, and economic (but not cultural) operational ideology are also associated with being a conflicted conservative.

We then use a similar regression model to investigate general-level conflicted liberals. As with conflicted conservatives, operational ideology on economic issues is related to conflict. But in contrast to the conflicted conservatives in this and Ellis and Stimson's sample, being a conflicted liberal is not associated with lower levels of political knowledge or higher levels of religiosity. Indeed, there are few significant variables for this model, possibly due to blunt measure of the dependent variable: an indicator for general-level incongruence between operational and symbolic ideology. We thus turn to our more finely-grained, issue-level measures for further analyses of both conflicted liberals and conflicted conservatives.

Ideological Incongruence at the Issue Level. The models of issue-level mismatches are reported in Table 6, where the dependent variable is the number of mismatches. There are two 
models, one for each direction of mismatch. ${ }^{2}$ Predicted effects for the significant variables are then plotted in Figure 3.

Ideological identities have the hypothesized effects on issue-label incongruence: conservatives (and moderates) are more likely than liberals to use the conservative label for liberal positions, while liberals (and, again, moderates) are more likely than conservatives to refer to conservative positions as liberal. In addition, the predicted effects in Figure 3 show that while liberals are roughly as likely to make either sort of mismatch, conservatives are much more likely to overuse the conservative label.

With respect to partisan identities, Democrats are significantly less likely (than Independents) to be conflicted liberals at the issue level; they are not, however, any more likely to use the conservative label for any liberal positions they may take. Republicans are significantly more likely to be conflicted conservative at the issue level, again, when compared with Independents, but they show no diminished propensity for describing conservative positions as liberal. These effects can be easily seen in Figure 3. In addition the figure shows that both Democrats and Republicans are more likely to mismatch conservative labels to liberal positions. This is a departure from the predicted effects for ideological identities, where liberals are as likely to make either kind of mismatch.

\footnotetext{
${ }^{2}$ Note that because we expect some of the explanatory variables to have differently signed effects across the two directions, such as holding a liberal or conservative identity, it does not make sense to combine the two forms of mismatch - in other words, to have a single model predicting issue-label mismatches regardless of direction. If such a model is specified (see Table S2 in the supplementary materials), such effects get cancelled out.
} 
With respect to ethnic identity, Figure 2 shows that black or Hispanic identifiers have elevated probabilities of making conservative position-liberal label mismatches compared to other ethnic groups (but not liberal position-conservative label mismatches). ${ }^{3}$

Like Ellis and Stimson, we find that being knowledgeable about politics reduces ideological incongruence. This effect can be seen in the predicted effects plots in Figure 3: low political knowledge is associated with a .70 probability of using the conservative label for a liberal position, dropping to .42 for high levels of knowledge. The effect is even more pronounced for conflicted liberal mismatches, moving from .44 at high knowledge to .17 at low knowledge.

Unlike Ellis and Stimson, who did not explore news sources, we find evidence that particular media outlets shape ideological inconsistency. In particular, watching Fox News has a significant effect on the propensity to mismatch liberal issue positions and conservative labels. Our model predicts that, holding all other variables constant, watching Fox News increases the likelihood of using the conservative label for a liberal position from .50 to .64 compared to people obtaining their news from other sources. The hypothesis that MSNBC has the equivalent effect on mislabeling conservative policy preferences as liberal is not supported. It therefore appears that the effect of Fox News on ideological inconsistency is unique among media outlets.

For examining the effect of age, we also include a quadratic term to capture the nonlinear hypothesis suggested by Ellis and Stimson: that the 1960s were something of a watershed in

\footnotetext{
${ }^{3}$ Note that because Asian Americans, as a group, have experienced less poverty than African- or Hispanic-Americans, we do not hypothesize that Asian ethnic identifiers will show increased conservative position-liberal label ideological incongruence; nor is there any evidence of such an effect.
} 
public approval of the liberal identity. These effects are most easily visualized in the predicted effects plot of Figure 3. Although only the coefficient of the quadratic term of age in the conflicted conservatism model is significant at the 95 percent confidence level, the signs of both quadratic terms are supportive of the Ellis and Stimson thesis. The propensity to be a conflicted conservative at the issue level is lowest among the oldest respondents, peaks just before the age of 50, before falling again for younger respondents. Age then shows a mirror-image effect on conflicted liberalism: older and younger respondents are most likely to use the liberal label for conservative policies, with those in their 50s least likely to do so.

Central to this analysis of Ellis and Stimson is the role of extra-political interpretations of ideological labels, largely due to the influence of religious conservatism in individuals' ideological identities. To measure religiosity, an additive scale of respondents' answers to four questions (see Table S1 in the supplementary materials) regarding levels of church attendance, belief in God, and frequency of prayer was created. Consistent with this previously defined pathway, our regression shows that greater religiosity is associated with a higher frequency of liberal position-conservative label mismatches. ${ }^{4}$ Religiosity does not appear to have an effect on the frequency of conservative position-liberal label mismatches. The contrasting slopes for these two effects are visible in Figure 3. Respondents who are not religious at all show little difference in their propensity to make either kind of labeling error (probabilities $=.32$ and .24 ). The very religious are much more likely to make liberal position-conservative label mismatches (probability $=.63)$ than conservative position-liberal label mismatches (probability $=.24)$.

\footnotetext{
${ }^{4}$ We checked whether religious affiliation-Catholic, Protestant, Jewish, etc.- - has an effect on ideological incongruence. It does not, regardless of the direction of mismatch. This analysis is available from the authors upon request.
} 
Finally, the effects of economic and cultural beliefs confirms the initial pattern observed in Figure 2: both domains of ideology play a role in conflicted liberalism, but only economic beliefs matter for conflicted conservatism. The more liberal an individual's economic and cultural operational ideologies, the less the issue-label inconsistency; the more conservative an individual's economic ideology, the same. These belief systems constrain issue-label matches, decreasing incongruence. The lack of an effect of cultural ideology on conflicted conservatism suggests that the latter is not merely a function of the two-dimensional issue space. ${ }^{5}$

We should point out, however, that there is another way, not tested here, that two dimensions of ideology might result in operational-symbolic conflict. If individuals vary in the salience they ascribe to either the economic and cultural dimensions, as Feldman and Johnston (2013) and Baldassari and Goldberg (n.d.) suggest, then they would be more likely to make issue-label mismatches. We leave this possibility to be tested in further analyses.

\section{Conclusion}

As a number of researchers have noted, one of the most puzzling features of ideology in the American public is the incongruence between the conservative majority, when ideology is viewed symbolically, and the liberal majority, when ideology is examined operationally. We contribute to the understanding of this incongruence by gathering and examining new issue-level measures of ideological incongruence.

\footnotetext{
${ }^{5}$ Note that we also ran both issue levels models using only mismatches on economic and cultural
} issues. The effects are similar within direction and across issue domain, with perhaps one exception: Republicans show more conflicted conservatism on economic but not cultural issues. Results are available in the supplementary materials (Tables S3 and S4). 
Using these more finely-grained measures, we confirm a number of the descriptive findings made in Ellis and Stimson's (2012) landmark study of ideology. First, we show that the more common form of incongruence is the labeling of liberal issue positions as conservative. More than 40 percent of conservatives, and more than 30 percent of the entire sample, hold at least one liberal position and describe this position as conservative.

Second, Ellis and Stimson suggest that these "conflicted conservatives" are, for the most part, conflicted on the issues of social spending. We find that this indeed the case: 20 percent of conservatives actually hold a liberal position on education spending but regard their position as conservative. The percentage doing the same for social security spending is 15 percent.

Third, Ellis and Stimson explain this ideological incongruence as the product of three pathways: ideological constraint, elite frames, and apolitical sources of labeling, particularly religious values. Our analysis supports their argument by showing that lower knowledge and higher religiosity is strongly associated with increased levels of liberal position-conservative label mismatches. We also include a number of additional tests of the elite framing pathway. We find that watching Fox News and being around 50 years of age increases the likelihood of issuelevel conflicted conservatism.

We also go on to extend the findings of Ellis and Stimson. First, following Popp and Rudolph (2011), we give greater emphasis to group identities. Ideological, partisan, and ethnic identities, we argue, might be expected to shape individual issue positions and ideological labels through the process of social identification. Indeed, we find evidence that both ideological and partisan identities shape the likelihood of describing one's liberal issues positions as conservative. In particular, both conservatives and Republicans are independently more likely to do so than liberals and Independents. 
Second, we also document and examine ideological incongruence in a symbolically liberal direction—describing one's conservative positions as being liberal. While less prevalent than Ellis and Stimson's "conflicted conservatives," we find that over 20 percent of our sample make at least one of these labeling mismatches.

As with liberal position-conservative label mismatches, we find that both ideological and partisan identities affect the propensity to make these conservative positions-liberal label mismatches. But our analysis reveals that this pattern of ideological incongruence is also shaped by ethnic identities: both African Americans and Hispanics, being groups that stand to benefit from liberal policies, tend to use the liberal label even for conservative policy positions.

Finally, we consider the role played by economic versus cultural issues in the conflict between positions and labels, as suggested by the bidimensionality arguments of Shafer and Claggett (1995), Feldman and Johnston (2013), Treier and Hillygus (2009), and others. We find that conflicted conservatism largely occurs on economic issues, while conflicted liberalism emanates from issues on both dimensions. Because we do not have data on the salience of dimensions, we consider the evidence quite tentative and deserving of further investigation.

\section{References}

Alvarez, R. Michael and John Brehm. 1995. “American Ambivalence towards Abortion Policy: Development of a Heteroskedastic Probit Model of Competing Values.” American Journal of Political Science. 39:1055-1082

Alvarez, R. Michael and John Brehm. 2002. Hard Choices, Easy Answers: Values, Information, and American Public Opinion. Princeton, NJ: Princeton University Press.

Baldassarri, Delia, and Amir Goldberg. n.d. 'Neither Ideologues, nor Agnostics: Alternative Voters' Belief System in an Age of Partisan Politics." 
Beatty, Kathleen M. and Oliver Walter. 1989. “A Group Theory of Religion and Politics.” Political Research Quarterly. 42:129-146.

Best, Samuel J., Brian Chmielewski, and Brian S. Krueger. 2005. "Selective Exposure to Online Foreign News during the Conflict with Iraq." The International Journal of Press/Politics. 10:52-70.

Boninger, David S., Jon A. Krosnick, and Matthew K. Berent. 1995. "The Causes and Consequences of Attitude Importance.” In R.E. Petty \& J.A. Krosnick (Eds.) Attitude Strength: Antecedents and Consequences 159-189. Hillsdale, New Jersey: Erlbaum.

Box-Steffensmeier, Janet M., Kathleen Knight, and Lee Sigelman. 1998. “The Interplay of Partisanship and Ideology: A Time-Series Analysis.” Journal of Politics 60(4): 1044-62.

Cantril, Albert H., and Susan D. Cantril. 1999. Reading Mixed Signals: Ambivalence in American Public Opinion about Government. Washington, DC: Woodrow Wilson Center Press.

Campbell, Angus, Philip E. Converse, Warren E. Miller, and Donald E. Stokes. 1960. The American Voter. New York: John Wiley \& Sons.

Clawson, Rosalee A. and Rakuya Trice. 2000. "Poverty as We Know It: Media Portrayals of the Poor." Public Opinion Quarterly. 64:53-64.

Conover, Pamela Johnston, and Stanley Feldman. 1981. "The Origins and Meanings of Liberal / Conservative Self-Identification.” American Journal of Political Science. 25: 617-645.

Conover, Pamela Johnston. 1984. “The Influence of Group Identifications on Political Perception and Evaluation." The Journal of Politics 46(3): 760-785.

Converse, Philip E. 1964. “The Nature of Belief Systems in Mass Publics.” In Ideology and Discontent, ed. David E. Pater. New York: Free Press

Ellis, Christopher, and James A. Stimson. 2007. Pathways to Ideology in American Politics: The Operational-Symbolic Paradox Revisited. Unpublished manuscript.

Ellis, Christopher, and James A. Stimson. 2012. Ideology in America. New York: Cambridge University Press. 
Erikson, Robert S., Michael B. MacKuen, and James A. Stimson. 2002. The Macro Polity. New York: Cambridge.

Delli-Carpini, Michael X. and Scott Keeter. 1996. What Americans Know About Politics and Why It Matters. New Haven: Yale University Press.

Feldman, Stanley. 1988. "Structure and Consistency in Public Opinion: The Role of Core Beliefs and Values.” American Journal of Political Science. 32: 416-438.

Feldman, Stanley and Christopher Johnston. 2013. "Understanding the Determinants of Political Ideology: Implications of Structural Complexity.” Political Psychology. n.d.

Feldman, Stanley and Marco Steenbergen. 2001. "Public Welfare Attitudes and the Humanitarian Sensibility," in James Kuklinski (ed.), Political Psychology and Public Opinion, Cambridge: Cambridge University Press.

Fiorina, Morris P., Samuel J. Abrams, and Jeremy C. Pope. 2005. Culture War? The Myth of a Polarized America. New York: Longman.

Free, Lloyd A. and Hadley Cantril. 1967. The Political Beliefs of Americans. New Brunswick, NJ: Rutgers University Press.

Gelman, Andrew, and Jennifer Hill. 2007. Data Analysis Using Regression and Multilevel/Hierarchical Models. New York: Cambridge University Press.

Gilens, Martin. 2000. Why Americans Hate Welfare: Race, Media, and the Politics of Anti-Poverty Policy. Chicago: University of Chicago Press.

Goren, Paul. 2004. "Political Sophistication and Policy Reasoning: A Reconsideration.” American Journal of Political Science. 48:462-478.

Goren, Paul. 2005. "Party Identification and Core Political Values.” American Journal of Political Science. 49:882-897.

Green, Donald, Bradley Palmquist, and Eric Schickler. 2002. Partisan Hearts and Minds: Political Parties and the Social Identities of Voters. New Haven: Yale University Press. 
Iyengar, Shinto. 1991. Is Anyone Responsible? How Television Frames Political Issues. Chicago: University of Chicago Press.

Jacoby, William G. 1991. "Ideological Identification and Issue Attitudes.” American Journal of Political Science 35: 178-205.

Jacoby, William G. 2000. "Issue Framing and Public Opinion on Government Spending.” American Journal of Political Science 44:750-767

Jennings, M. Kent. 1992. “Ideological Thinking Among Mass Publics and Political Elites.” Public Opinion Quarterly. 56:419-441.

Judd, Charles and Jon Krosnick. 1989. "The Structural Bases of Consistency Among Political Attitudes: Effects of Political Expertise and Attitude Importance.” In Anthony R. Pratkanis, Steven J. Breckler, and Anthony G. Greenwald (Eds.), Attitude Structure and Function. Hillsdale, NJ: Erlbaum.

Kellstedt, Lyman, and Corwin Smidt. 1991. "Measuring Fundamentalism: An Analysis of Different Operational Strategies.” Journal for the Scientific Study of Religion. 30: 259-278.

Knight, Kathleen. 1985. “Ideology in the 1980 Election: Ideological Sophistication Does Matter.” Journal of Politics 47: 828-853.

Layman, Geoffrey C., and Thomas Carsey. 2002. "Party Polarization and 'Conflict Extension' in the American Electorate.” American Journal of Political Science. 46:786-802.

Leege, David C. and Lyman A. Kellstedt. 1993. Rediscovering the Religious Factor in American Politics. New York: M.E. Sharpe

Miller, Alan S. 1992. “Are Self-Proclaimed Conservatives Really Conservative? Trends in Attitudes and Self-Identification Among the Young.” Social Forces 71: 195-210.

Miller, Arthur H., Patricia Gurin, Gerald Gurin, and Oksana Malanchuk. 1981. "Group Consciousness and Political Participation.” American Journal of Political Science 25(3): 494-511

Mutz, Diana C. 2006. Hearing the Other Side: Deliberative Versus Participatory Democracy. New York: Cambridge University Press. 
Mutz, Diana C. and Paul S. Martin. 2001. "Facilitating Communication across Lines of Political Difference: The Role of Mass Media.” The American Political Science Review 95:97-114.

Popp, Elizabeth and Thomas J. Rudolph. 2011. “A Tale of Two Ideologies: Explaining Public Support for Economic Interventions.” The Journal of Politics. 73:808-820.

Putnam, Robert D. and David E. Campbell. 2010. American Grace: How Religion Divides and Unites Us. New York: Simon and Schuster

Reese, Stephen D., Oscar H. Gandy, and August E. Grant. 2001. Framing Public Life: Perspectives on Media and Our Understanding of the Social World. Mahwah, NJ: Erlbaum.

Robinson, John P., and John A. Fleishman. 1988. "Ideological Identification: Trends and Interpretations of the Liberal-Conservative Balance.” Public Opinion Quarterly 52: 134-145.

Robinson, John P., and John A. Fleishman. 1984. "Trends in Ideological Identification in the American Public," Annals of Political and Social Science 472: 50-60.

Rubin, Donald B. 1987. Multiple Imputation for Nonresponse in Surveys. New York: Wiley.

Schiffer, Adam J. 2000. "I'm Not That Liberal: Explaining Conservative Democratic Identification." Political Behavior. 22: 293-310.

Shafer, Byron E. and William Jennings Claggett. 1995. The Two Majorities: The Issue Context of Modern American Politics. Baltimore, MD: Johns Hopkins University Press.

Sears, David O. and Jack Citrin. 1985. Tax Revolt: Something for Nothing in California. Cambridge: Harvard University Press.

Sears, David O. and C.L. Funk. 1990. “Self-Interest in Americans' Political Opinions.” in J.J. Mansbridge (Ed.) Beyond Self-Interest. Chicago: University of Chicago Press, pp. 147-170.

Smith, Tom W. 1990. "Liberal and Conservative Trends in the United States since World War II." Public Opinion Quarterly 54: 479-507.

Sniderman, Paul M. and Edward H. Stigliz. 2012. The Reputational Premium: A Theory of Party Identification and Reasoning. Princeton: Princeton University Press. 
Stimson, James A. 1975. "Belief Systems: Constraint, Complexity, and the 1972 Election." American Journal of Political Science 19(3): 393-417.

Stimson, James A. 1999. Public Opinion in America: Moods, Cycles, and Swings. 2nd Ed. Boulder, CO: Westview Publishing.

Stimson, James A. 2004. Tides of Consent. New York: Cambridge University. Press.

Stroud, Natalie J. 2008. "Media Use and Political Predispositions: Revisiting the Concept of Selective Exposure.” Political Behavior. 30: 341-366.

Taber, Charles, S. and Milton Lodge. 2006. "Motivated Skepticism in the Evaluation of Political Beliefs." American Journal of Political Science. 50:755-769.

Tajfel, Henri. 1981. Human Groups and Social Categories. Cambridge: Cambridge University Press.

Treier, Shawn and D. Sunshine Hillygus. 2009. "The Nature of Political Ideology in the Contemporary Electorate", Public Opinion Quarterly. 73:679-703.

Turner, John C. 1991. Social Influence. Belmont, CA: Thomson Brooks/Cole.

Turner, John C., Michael A. Hogg, Penelope J. Oakes, Stephen D. Reicher, and Margaret S. Wetherell. 1987. Rediscovering the Social Group: A Self-Categorization Theory. Oxford: Blackwell.

Wittkopf, Eugene R. 1990. Faces of Internationalism: Public Opinion and American Foreign Policy. Durham: Duke University Press.

Zaller, John R. 1992. The Nature and Origins of Mass Opinion. Cambridge: Cambridge University Press. Zschirnt, Simon. 2011. "The Origins and Meaning of Liberal/Conservative Self-Identifications Revisited.” Political Behavior. 33:685-701.

Zumbrunnen, John and Amy Gangl. 2008. "Conflict, Fusion, or Coexistence? The Complexity of Contemporary American Conservatism.” Political Behavior. 30:199-221. 
Figure 1. Aggregated Usage of Issue Labels By Symbolic Ideology

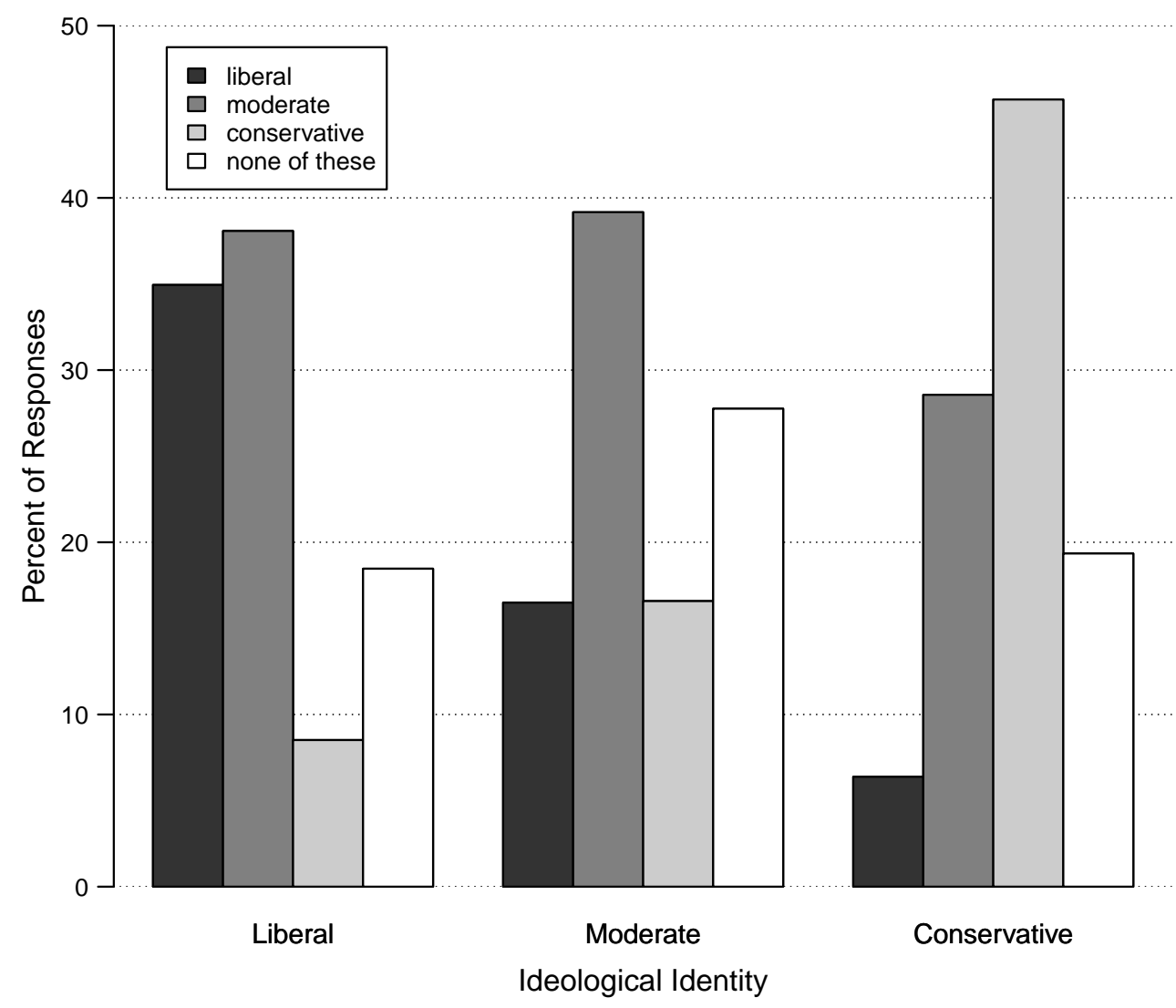

Bars indicate the frequency distribution of the four issue labels, aggregated across the 14 policy items and within categories of symbolic ideology. 
Figure 2. Position-Label Mismatches by Policy Issue and Direction of Mismatch

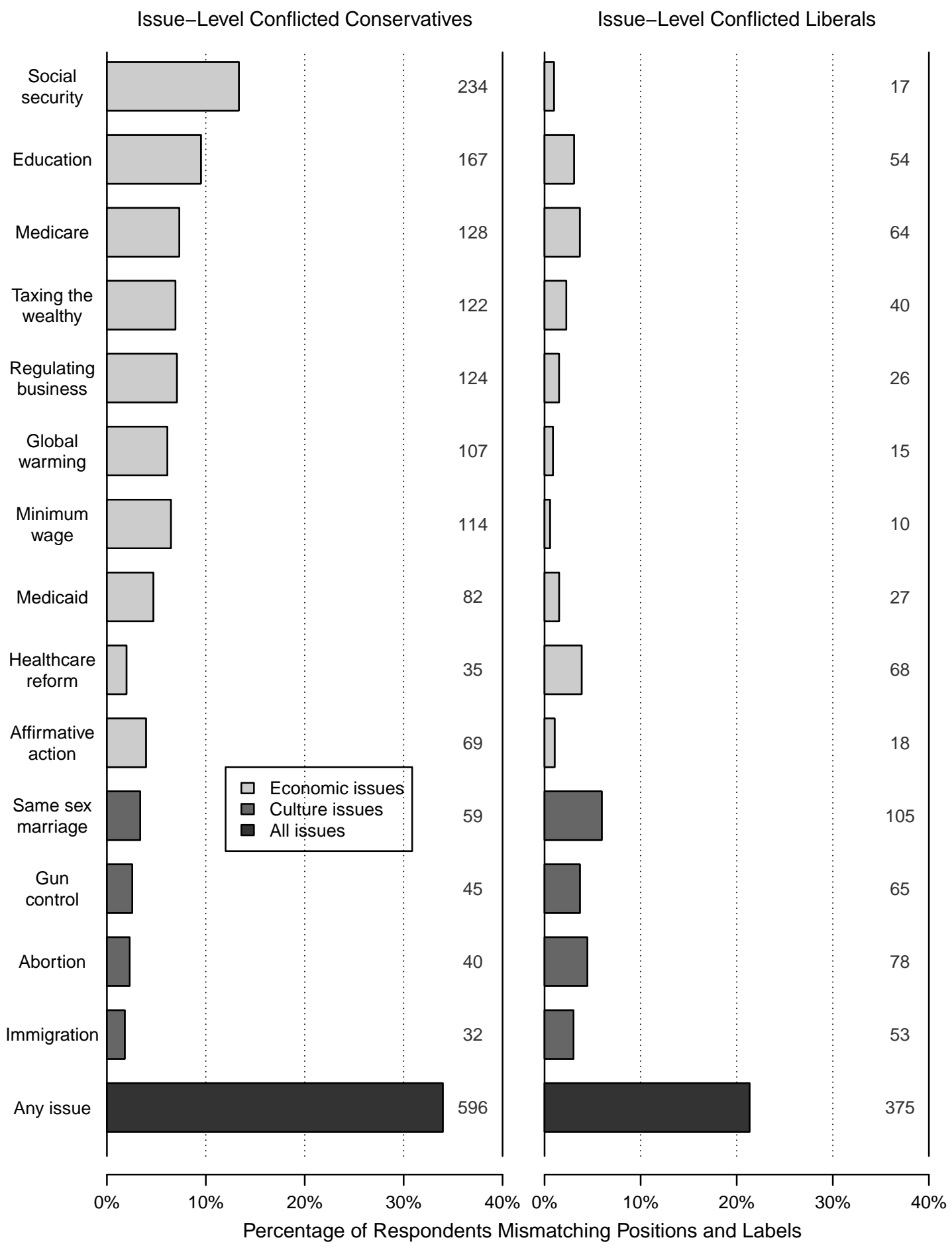

Bars indicate the proportion of respondents making a policy-label mismatch. There are two possible kinds of labeling errors: expressing a liberal policy preference but labeling this preference as conservative (first column), or expressing a conservative preference and labeling it liberal (last column). Rows are the 14 policy issues. Numbers in grey are the number of respondents making the corresponding mismatch. 


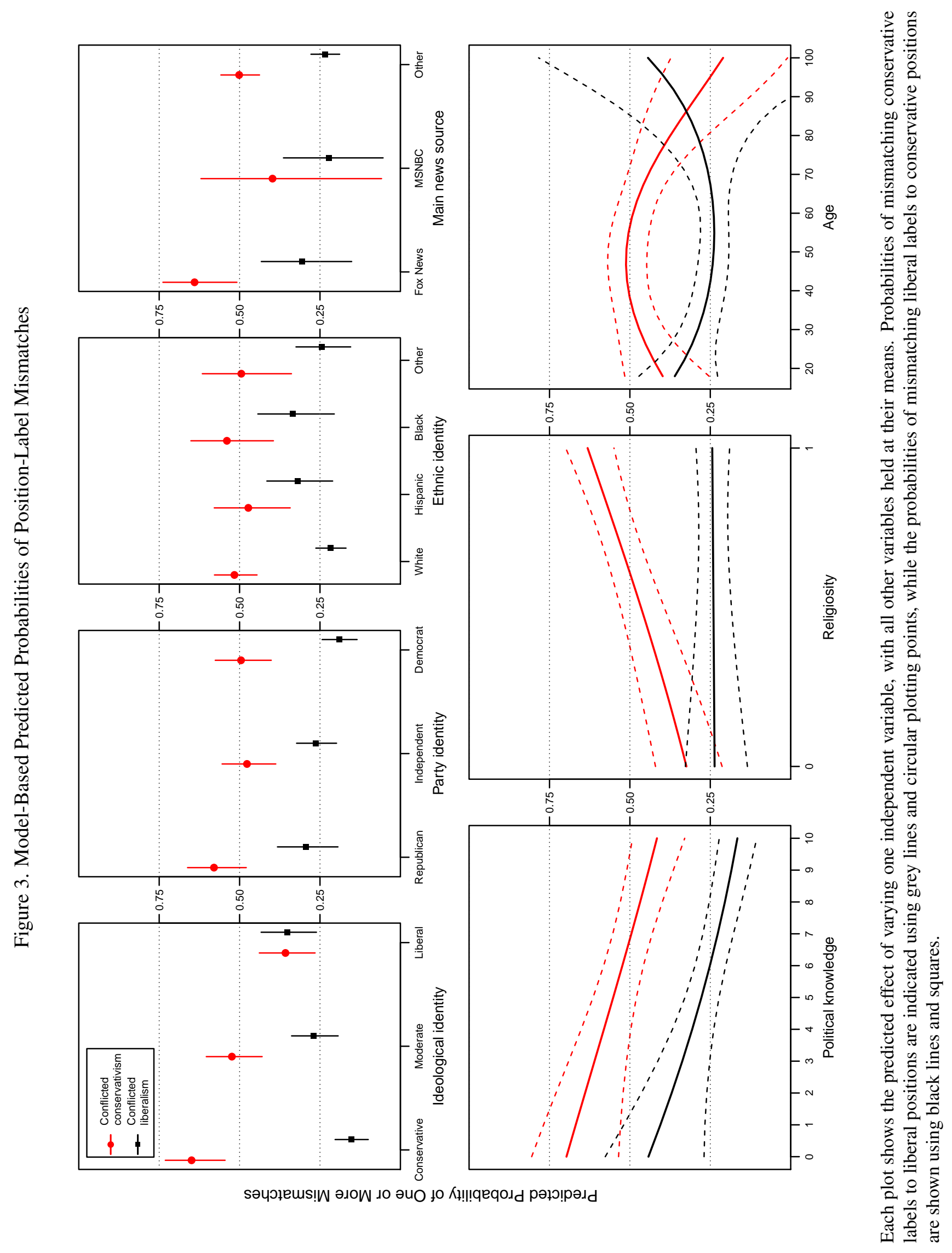


Table 1. Four Conceptions of Political Preferences

\begin{tabular}{c|c|c|}
\multicolumn{1}{c|}{ Symbolic } & Operational \\
\cline { 2 - 3 } General level & Symbolic ideology & Operational ideology \\
\cline { 2 - 3 } Issue level & Issue label & Issue position \\
\cline { 2 - 3 } & & \\
\hline
\end{tabular}


Table 2. General Level Mismatches Between Symbolic and Operational Ideology

\begin{tabular}{|c|c|c|c|c|c|}
\hline \multirow{2}{*}{$\begin{array}{l}\text { Operational } \\
\text { ideology }\end{array}$} & \multicolumn{5}{|c|}{ Symbolic ideology } \\
\hline & & Liberal & Moderate & Conservative & Total \\
\hline Liberal & $\begin{array}{l}\text { Row \% } \\
N \\
\text { Column \% }\end{array}$ & $95.2^{(514)^{44.5}}$ & $76.7^{(449)^{38.9}}$ & $\begin{array}{c}\text { (192) } \\
30.5 \\
\text { Conflicted } \\
\text { conservatives }\end{array}$ & 65.8 \\
\hline Conservative & $\begin{array}{l}\text { Row \% } \\
N \\
\text { Column \% }\end{array}$ & $\begin{array}{c}4.3 \\
4.8 \\
\text { Conflicted } \\
\text { liberals }\end{array}$ & $23.3^{(136)^{22.7}}$ & $69.5^{(439)^{73.0}}$ & 34.2 \\
\hline Total & Column \% & 30.7 & 33.3 & 35.9 & \\
\hline
\end{tabular}

Cross-tabulation of operation and symbolic ideology at the general level (the first row in Table 1). Numbers in the upper right of each cell are row percentages (within categories of operational ideology), while those on the centre left are column percentages (within categories of symbolic ideology. Sample sizes and percentages are weighted and averaged across the ten imputed datasets. For the purposes of this analysis, operational ideology is calculated as follows: any liberal response to a policy question is coded as -1 , a conservative response, +1 , and an uncertain response, 0 . The scores are then summed across the 14 issues, such that a negative (positive) value reflects, on balance, a liberal (conservative) operational ideology. 
Table 3. Issue Level Mismatches Between Symbolic and Operational Ideology, Pooled Across 14 Issues

Issue positions
Symbolic label

Liberal Moderate None of these Conservative Total

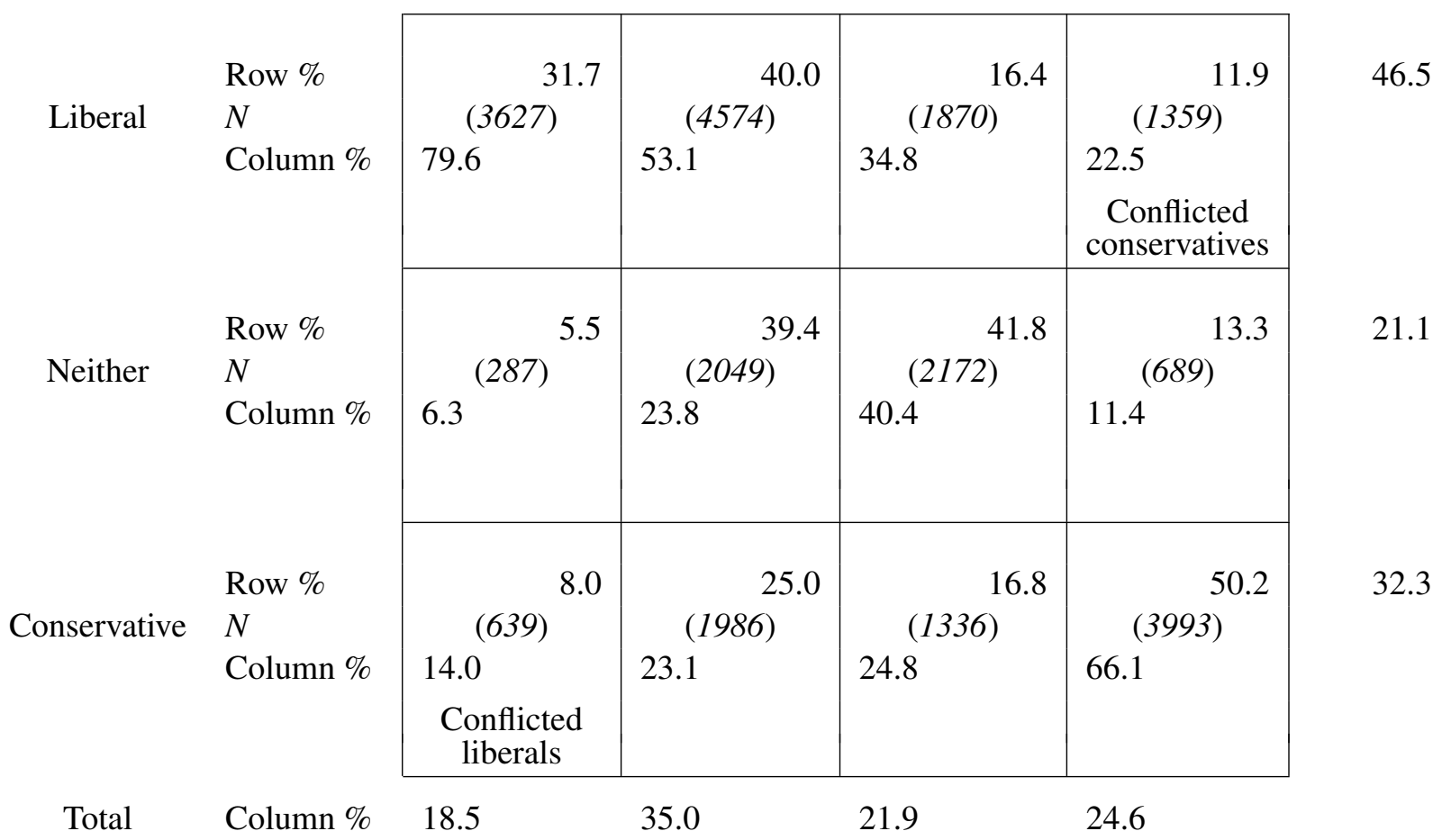

Cross-tabulation of issue positions and symbolic labels thereof (the second row in Table 1). Data are pooled across all 14 issues. Numbers in the upper right of each cell are row percentages (within issue positions), while those on the centre left are column percentages (within symbolic labels). Numbers in parentheses are the sample size, pooled across all 14 issues, within each cell. Sample sizes and percentages are weighted and averaged across the ten imputed datasets. 
Table 4. Frequency of "None of These" as a Label for Issue Positions, by Symbolic Ideology

\begin{tabular}{|c|c|c|c|c|c|}
\hline \multicolumn{2}{|r|}{ Liberals } & \multicolumn{2}{|r|}{ Moderates } & \multicolumn{2}{|r|}{ Conservatives } \\
\hline$\%$ & Issue & $\%$ & Issue & $\%$ & Issue \\
\hline 10.7 & taxing the wealthy & 21.5 & taxing the wealthy & 10.9 & education \\
\hline 12.7 & same sex marriage & 21.7 & education & 14.3 & same sex marriage \\
\hline 13.0 & abortion & 24.3 & Medicaid & 14.4 & taxing wealthy \\
\hline 14.1 & education & 24.4 & minimum wage & 14.7 & health care reform \\
\hline 16.2 & global warming & 25.6 & abortion & 15.1 & abortion \\
\hline 17.1 & gun control & 26.1 & global warming & 16.2 & gun control \\
\hline 17.5 & minimum wage & 26.7 & same sex marriage & 19.1 & immigration \\
\hline 18.2 & affirmative action & 27.6 & gun control & 20.2 & business regulation \\
\hline 18.9 & health care reform & 28.4 & immigration & 20.2 & minimum wage \\
\hline 20.0 & Medicaid & 29.8 & health care reform & 21.4 & global warming \\
\hline 21.0 & business regulation & 29.8 & business regulation & 21.9 & Medicaid \\
\hline 21.9 & immigration & 30.1 & affirmative action & 23.2 & affirmative action \\
\hline 26.1 & Medicare & 35.2 & Medicare & 28.6 & Social Security \\
\hline 31.2 & Social Security & 37.3 & Social Security & 29.4 & Medicare \\
\hline
\end{tabular}

Percent columns are the percentage of individuals in each category of ideological identity (liberal, moderate, conservative) who chose "none of these" as a label for their issue position. Rows are sorted in ascending order. 
Table 5. Determinants of General-Level Conflicted Conservatives and Liberals

\begin{tabular}{|c|c|c|c|c|}
\hline \multirow[t]{2}{*}{ Dependent variable: whether respondent is a... } & \multicolumn{2}{|c|}{$\begin{array}{l}\text { Conflicted } \\
\text { liberal }\end{array}$} & \multicolumn{2}{|c|}{$\begin{array}{l}\text { Conflicted } \\
\text { conservative }\end{array}$} \\
\hline & .16 & $(.45)$ & $1.64^{*}$ & $(.23)$ \\
\hline $\begin{array}{l}\text { Partisan identity: }{ }^{b} \text { Republican } \\
\text { Partisan identity: Democrat }\end{array}$ & $\begin{array}{r}-.63 \\
.57\end{array}$ & $\begin{array}{l}(.81) \\
(.76)\end{array}$ & $\begin{array}{c}.34 \\
-1.18^{*}\end{array}$ & $\begin{array}{l}(.33) \\
(.29)\end{array}$ \\
\hline $\begin{array}{l}\text { Ethnic identity: }{ }^{c} \text { Hispanic } \\
\text { Ethnic identity: Black } \\
\text { Ethnic identity: Other race }\end{array}$ & $\begin{array}{c}-1.06 \\
-1.25 \\
-15.54^{*}\end{array}$ & $\begin{array}{r}(1.31) \\
(1.19) \\
(.45)\end{array}$ & $\begin{array}{l}.48 \\
.41 \\
.50\end{array}$ & $\begin{array}{l}(.28) \\
(.33) \\
(.39)\end{array}$ \\
\hline Political knowledge & -.51 & $(1.15)$ & $-1.88^{*}$ & $(.48)$ \\
\hline $\begin{array}{l}\text { Main news source: }{ }^{d} \text { Fox } \\
\text { Main news source: MSNBC }\end{array}$ & $\begin{array}{r}-1.43 \\
-.14\end{array}$ & $\begin{array}{l}(1.25) \\
(1.28)\end{array}$ & $\begin{array}{r}.10 \\
-.58\end{array}$ & $\begin{array}{l}(.33) \\
(.80)\end{array}$ \\
\hline $\begin{array}{l}\text { Age } \\
\text { Age squared }\end{array}$ & $\begin{array}{r}5.20 \\
-7.04\end{array}$ & $\begin{array}{l}(4.69) \\
(5.15)\end{array}$ & $\begin{array}{r}-2.62 \\
3.97\end{array}$ & $\begin{array}{l}(1.91) \\
(2.39)\end{array}$ \\
\hline $\begin{array}{l}\text { Religiosity } \\
\text { Religion: Evangelical Christian }\end{array}$ & $\begin{array}{l}.94 \\
.06\end{array}$ & $\begin{array}{r}(1.04) \\
(.61)\end{array}$ & $\begin{array}{c}1.31^{*} \\
.26\end{array}$ & $\begin{array}{l}(.44) \\
(.24)\end{array}$ \\
\hline $\begin{array}{l}\text { Operational ideology: economic } \\
\text { Operational ideology: cultural }\end{array}$ & $\begin{aligned} & 5.04^{*} \\
- & 1.23\end{aligned}$ & $\begin{array}{l}(1.71) \\
(1.43)\end{array}$ & $\begin{array}{c}-5.21^{*} \\
.02\end{array}$ & $\begin{array}{l}(.82) \\
(.62)\end{array}$ \\
\hline $\begin{array}{l}\text { Gender: female } \\
\text { Education } \\
\text { Region: South } \\
\text { Income }\end{array}$ & $\begin{array}{c}-.16 \\
-4.13^{*} \\
.48 \\
.05\end{array}$ & $\begin{array}{r}(.57) \\
(1.45) \\
(.54) \\
(1.44)\end{array}$ & $\begin{array}{r}.34 \\
-1.06 \\
.23 \\
1.28\end{array}$ & $\begin{array}{l}(.21) \\
(.72) \\
(.20) \\
(.68)\end{array}$ \\
\hline
\end{tabular}

${ }^{*} p<.05$

${ }^{a}$ Intensity, not valence, of symbolic ideology.

${ }^{b}$ Omitted category is Independents.

${ }^{c}$ Omitted category is White.

${ }^{d}$ Omitted category is all other news sources.

${ }^{e}$ Conservative $=$ high.

$N=1725$. Standard errors in parentheses. All variables rescaled to the $[0,1]$ interval. Estimates obtained using logit regression models for complex survey data, combined for the ten multiply-imputed datasets. Intercepts not shown. 
Table 6. Determinants of Issue-Level Conflicted Conservatism and Liberalism

\begin{tabular}{|c|c|c|c|c|c|}
\hline & \multirow[b]{2}{*}{ Dependent variables: } & \multicolumn{2}{|c|}{ Conflicted liberalism: } & \multicolumn{2}{|c|}{ Conflicted conservatism: } \\
\hline & & \multicolumn{2}{|c|}{$\begin{array}{l}\text { No. of liberal labels } \\
\text { used for conservative } \\
\text { positions (out of 14) }\end{array}$} & \multicolumn{2}{|c|}{$\begin{array}{c}\text { No. of conservative labels } \\
\text { used for liberal } \\
\text { positions (out of 14) }\end{array}$} \\
\hline $\begin{array}{l}\text { Symbolic ideology: Conservative } \\
\text { Symbolic ideology: Moderate } \\
\text { Symbolic ideology: Liberal }\end{array}$ & & $\begin{array}{l}.63^{*} \\
.95^{*}\end{array}$ & $\begin{array}{l}(.23) \\
(.24)\end{array}$ & $\begin{array}{l}.89^{*} \\
.53^{*}\end{array}$ & $\begin{array}{l}(.21) \\
(.20)\end{array}$ \\
\hline $\begin{array}{l}\text { Partisan identity: }{ }^{a} \text { Republican } \\
\text { Partisan identity: Democrat }\end{array}$ & & $\begin{array}{c}.13 \\
-.38^{*}\end{array}$ & $\begin{array}{l}(.21) \\
(.16)\end{array}$ & $\begin{array}{l}.30^{*} \\
.05\end{array}$ & $\begin{array}{l}(.15) \\
(.17)\end{array}$ \\
\hline $\begin{array}{l}\text { Ethnic identity: }{ }^{b} \text { Hispanic } \\
\text { Ethnic identity: Black } \\
\text { Ethnic identity: Other }\end{array}$ & & $\begin{array}{l}.47^{*} \\
.53^{*} \\
.14\end{array}$ & $\begin{array}{l}(.20) \\
(.22) \\
(.20)\end{array}$ & $\begin{array}{r}-.13 \\
.06 \\
-.07\end{array}$ & $\begin{array}{l}(.18) \\
(.19) \\
(.21)\end{array}$ \\
\hline Political knowledge & & $-1.21^{*}$ & $(.35)$ & $-.83^{*}$ & $(.27)$ \\
\hline $\begin{array}{l}\text { Main news source: }{ }^{c} \text { Fox } \\
\text { Main news source: MSNBC }\end{array}$ & & $\begin{array}{r}.24 \\
-.02\end{array}$ & $\begin{array}{l}(.29) \\
(.43)\end{array}$ & $\begin{aligned} & .43^{*} \\
- & -37\end{aligned}$ & $\begin{array}{l}(.18) \\
(.43)\end{array}$ \\
\hline $\begin{array}{l}\text { Age } \\
\text { Age squared }\end{array}$ & & $\begin{array}{r}-2.38 \\
2.76\end{array}$ & $\begin{array}{l}(1.33) \\
(1.91)\end{array}$ & $\begin{array}{c}1.96 \\
-2.72^{*}\end{array}$ & $\begin{array}{l}(1.12) \\
(1.38)\end{array}$ \\
\hline $\begin{array}{l}\text { Religiosity } \\
\text { Religion: Evangelical Christian }\end{array}$ & & $\begin{array}{l}-.01 \\
-.02\end{array}$ & $\begin{array}{l}(.26) \\
(.16)\end{array}$ & $\begin{aligned} & .97^{*} \\
&-.25\end{aligned}$ & $\begin{array}{l}(.24) \\
(.13)\end{array}$ \\
\hline $\begin{array}{l}\text { Operational ideology: }{ }^{d} \text { economic } \\
\text { Operational ideology: cultural }\end{array}$ & & $\begin{array}{r}1.14^{*} \\
.90^{*}\end{array}$ & $\begin{array}{l}(.51) \\
(.44)\end{array}$ & $\begin{array}{c}-2.04^{*} \\
.20\end{array}$ & $\begin{array}{l}(.38) \\
(.36)\end{array}$ \\
\hline $\begin{array}{l}\text { Gender: female } \\
\text { Education } \\
\text { Region: South } \\
\text { Income }\end{array}$ & & $\begin{array}{r}-.13 \\
-.81 \\
.05 \\
.33\end{array}$ & $\begin{array}{l}(.15) \\
(.51) \\
(.14) \\
(.46)\end{array}$ & $\begin{array}{r}.03 \\
-.66 \\
-.10 \\
-.68\end{array}$ & $\begin{array}{l}(.10) \\
(.41) \\
(.12) \\
(.37)\end{array}$ \\
\hline
\end{tabular}

${ }^{*} p<.05$.

${ }^{a}$ Omitted category is Independents.

${ }^{b}$ Omitted category is White.

${ }^{c}$ Omitted category is all other news sources.

${ }^{d}$ Conservative $=$ high .

$N=1725$. Standard errors in parentheses. Estimates obtained using overdispersed logistic-binomial regression models for complex survey data, combined for the ten multiply-imputed datasets. Intercept not shown. 